\title{
Membangun Loyalitas Pelanggan "Citilink" Garuda: Tinjauan Manajemen Hubungan Pelanggan
}

\author{
Prima Mulyasari Agustini
}

\begin{abstract}
Building a loyal customer community is the aim of transportation business. Citilink as one of national flag carrier manages its customer relation by maintaining communication among customer, corporate, and workforce. Using communication management approach to build a close connection among its customers, Citilink focused on 4 aspects: makes regular repeat purchase, purchases across products and service lines, refers others, and demonstrates immunity to the pull of competition. A system of customer satisfaction fulfillment needs to be established to ensure customer loyalty.
\end{abstract}

Kata kunci: manajemen hubungan pelanggan, loyalitas pelanggan, jasa penerbangan

\section{Latar Belakang}

Industri transportasi di Indonesia mulai menggeliat kembali setelah dihantam badai krisis di tahun 1998. Krisis ekonomi berkepanjangan, menghempaskan industri ini, dengan kenaikan biaya opersaional moda, baik darat, laut, maupun udara. Krisis ini begitu terasa pada industri penerbangan. Tingginya biaya opersioanal dan avtur yang merupakan bahan bakar pesawat, telah memaksa beberapa perusahaan penerbangan gulung tikar.

Namun, dengan adanya kebijakan baru pemerintah mengenai open sky policy, telah membuat industri penerbangan kembali ramai.
Menjadi pemain di industri ini semakin mudah, dimana pemerintah menetapkan bahwa perusahaan maskapai penerbangan bisa dibuka, minimal memiliki dua pesawat, baik milik sendiri maupun leasing. Pada tahun 2003 saja, terdapat 31 perusahaan penerbangan yang melayani penumpang pesawat di seluruh Indonesia.

Selain itu, pada tahun 2001, pemerintah menetapkan tarif batas atas untuk maskapai penerbangan. Dampak dari kebijakan ini adalah, terjadinya saling banting harga antarmaskapai penerbangan. Para pebisnis ini berlomba menurunkan harga tiket yang serendah-rendahnya, walaupun margin kecil, namun perusahaan berupaya mengejar kuantitas. Memang pemerintah 
tidak menetapkan batas bawah tarif penerbangan. Tentu saja ini, sangat menguntungkan bagi konsumen Indonesia, yang cenderung sensitif terhadap harga.

PT Garuda Indonesia sebagai market leader di industri ini, tentu tidak mau ketinggalam untuk mendapatkan laba dari kebijakan baru pemerintah ini. Garuda meluncurkan Citilink sebagai produk menengah ke bawah, yang dipasarkan dengan memanfaatkan kebijakan tidak adanya batas bawah tarif penerbangan. Citilink ini disediakan untuk memfasilitasi penumpang pesawat untuk jarak dekat.

Dengan strategi kepemimpinan biaya, di mana tarif yang ditawarkan lebih murah dari pada tarif regular Garuda, manajemen perusahaan tetap berupaya Citilink memiliki keunggulan bersaing dengan maskapai penerbangan lainnya, yang melayanai rute yang sama, untuk dapat mempertahankan loyalitas pelanggan. Salah satu cara mempertahankan loyalitas pelanggan adalah dengan membangun hubungan dengan pelanggan. Hubungan dengan pelanggan ini perlu dikelola dengan baik. Manajemen hubungan pelanggan Citilink Garuda perlu dilakukan agar pelanggan tetap loyal.

Sesuai dengan latar belakang di atas, maka rumusan masalah dalam makalah ini sebagai berikut: "bagaimana manajemen hubungan pelanggan Citilink Garuda dalam mempertahankan loyalitas pelanggan?

\section{Tinjauan Teoretis}

\subsection{Manajemen Hubungan Pelanggan}

Semakin tingginya peran konsumen bagi suatu perusahaan maka dirasakan perlu untuk menjalin hubungan yang lebih mendalam dan dalam jangka panjang dengan pelanggan atau yang lebih dikenal dengan istilah manajemen hubungan pelanggan (customer relationship manangement). Bernd $\mathrm{H}$. Schmitt (2003: 15) menyatakan bahwa menajemen hubungan pelanggan adalah suatu hubungan dengan pelanggan di mana antara pelanggan yang satu dengan pelanggan yang lainnya diberlakukan secara berbeda sesuai dengan kebutuhannya. Sementara, William G. Zikmund, dkk (2003:3) menyatakan bahwa manajemen hubungan pelanggan adalah: suatu proses dalam mengumpulkan berbagai informasi yang akan meningkatkan pemahaman mengenai bagaimana mengelola suatu hubungan perusahaan dengan pelanggannya.

Menurut Storbacka dan Lehtinen (2001:4) ada tiga konsep dari manajemen hubungan pelanggan. Konsep yang pertama adalah penciptaan nilai pelanggan yang bertujuan tidak hanya untuk memaksimalkan pendapatan dari transaksi tunggal, melainkan keunggulan bersaing yang tidak hanya berdasarkan harga, tetapi juga berdasarkan kemampuan provider untuk membantu pelanggan menghasilkan nilai untuk mereka sendiri dan untuk membina hubungan jangka panjang dengan pelanggan. Konsep kedua adalah dengan melihat produk sebagai suatu proses dalam hal ini perbedaan barang dan jasa tidak berarti lagi. Produk dilihat sebagai suatu entitas yang mencakup pertukaran antara proses yang dijalankan oleh provider dengan proses yang dijalankan oleh pelanggan. Melalui pertukaran ini kompetensi provider sebagian dipindahkan ke dalam penciptaan nilai pelanggan. Karena itu, diferensiasi produk menjadi diferensiasi proses sehingga membuka peluang yang tak terbatas yang menghasilkan berbagai macam hubungan. Konsep ketiga adalah tanggung jawab provider. Suatu perusahaan dapat membina hubungan yang lebih kuat hanya jika perusahaan bertanggung jawab dalam membangun hubungan tersebut dan menawarkan para pelanggannya untuk menghasilkan nilai-nilai untuk mereka sendiri.

Manajemen hubungan pelangan merupakan kombinasi dari proses bisnis dan teknologi yang tujuannya untuk memahami pelanggan dari berbagai prospektif untuk membedakan produk dan jasa perusahaan secara kompetitif (Tiwana; 2001:23). Fokus dari manajemen hubungan pelanggan itu sendiri adalah untuk memperbaiki tingkat kepuasan pelanggan, meningkatkan loyalitas pelanggan dan meningkatkan pendapatan dari pelanggan yang ada dalam menghadapi tingginya tingkat persaingan, globalisasi dan perputaran pelanggan serta 
perkembangan biaya pengakuisisian pelanggan.

Dengan diterapkannya manajemen hubungan pelanggan, memungkinkan perusahaan untuk memiliki kapabilitas untuk memahami perilaku pembelian pelanggan dengan lebih baik dan untuk menentukan tipe komunikasi yang bagaimana yang seharusnya dijalankan dalam menghadapi pelanggan. Pada dasarnya manajemen hubungan pelanggan adalah mengenali konsumen yang terbaik dan memberikan kepercayaan terhadap konsumen, memenuhi harapan mereka dan membuat hidup mereka berubah, maka konsumen suatu perusahaan tidask boleh diperlakukan secara sama (Storbacka dan Lehitnen; 2001: 42).

Manajemen hubungan pelanggan sebagai suatu fokus dalam menghasilkan nilai optimal bagi para pelanggan melalui bagaimana cara perusahaan berkomunikasi dengan pelanggan, bagaimana perusahaan memasarkannya, dan bagaimana perusahaan melayani mereka, serta melalui media trdisional yang meliputi produk, harga, promosi, dan distribusi (Nykamp, 2001:4).

Pelanggan melakukan keputusan pembelian tidak hanya berdasarkan harga dan produknya saja, tetapi berdasarkan keseluruhan pengalaman mereka yang mencakup produk dan harga serta seluruh interaksi mereka dengan perusahaan. Jika perusahaan dapat menyampaikan interaksi pemasaran, penjualan, jasa, serta dukungan secara konsisten, maka perusahaan akan diberikan penghargaan berupa loyalitas pelanggan dan nilai pelanggan, hal yang sangat penting dalam keunggulan bersaing.

\subsection{Loyalitas Pelanggan}

Menjadi pelanggan yang loyal adalah merupakan tujuan akhir dari semua perusahaan. Kebanyakan perusahaan tidak menyadari bahwa loyalitas pelanggan dibentuk melalui tahapan yang dimulai dari mencari calon pelanggan potensial sampai dengan advocate customer yang akan membawa keuntungan bagi perusahaan.

Menurut Kotler (2003: 687), customer loyalty is the purchases from the company by its customers expressed as a percentage of their total purchases from all suppliers of the same
products.Definisi loyalitas pelanggan, menurut Oliver (1997: 392), adalah: "Customer loyality is deeply held commitment to rebuy or to repatronize a prefffered product or service consistently in the future, despite situstional, influenced and marketing efforts having the potential to cause switching behavior." Sementara, Griffin (1995:4), menyatakan bahwa: "Loyalty is defined as non random purchase expressed over time by some decision making unit."

Pelanggan yang loyal merupakan aset yang berharga untuk perusahaan. Agar mencapai pelanggan yang loyal perusahaan harus mampu menawarkan produk/jasa yang dapat memenuhi harapan pelanggan serta dapat memuaskan perasaannya. Apabila pelanggan yang melakukan tindakan pembelian secara berulang dan teratur maka pelanggan tersebut adalah pelanggan yang loyal. Hal tersebut diperkuat dengan pernyataaan Griffin (1995: 31) bahwa karakteristik pelanggan yang loyal adalah:

(1) makes regular repeat purchase (melakukan pembelian ulang).

(2) purchases across product and service lines (membeli di luar lini produk atau jasa).

(3) refers others (menarik pelanggan baru untuk perusahaan)

(4) demonstrates an immunity to the pull of the competition (menolak produk / jasa lain, dan kebal terhadap daya tarik pesaing).

Sementara , David L. Stum (1994: 4) menyatakan, ada lima tipe perilaku pelanggan yang berdampak pada penjualan, pertumbuhan dan profitabilitas perusahaan, yaitu:

(1) repeat purchases (pembelian ulang)

(2) increased volume of purchases (meningkatkan volume pembelian)

(3) purchases across the total available product / service line (pembelian sejumlah lini jasa atau produk)

(4) referrals (memberi pelanggan baru)

(5) immunity from the 'pull' of the competition (kebal terhadap daya tarik pesaing)

Semua karakteristik di atas dapat terwujud jika pelanggan yang menggunakan produk atau jasa tertentu merasa terpuaskan oleh produk atau jasa 
tersebut. Pelanggan yang puas terhadap kualitas jasa/pelayanan yang baik akan senang melakukan pembelian atau menggunakan jasa secara berulang-ulang. Lebih lanjut mereka akan dengan mudah merekomendasikan kepada orang lain mengenai keunggulan suatu produk atau jasa. Bahkan, menurut Hermawan Kertajaya (1997: 478), orang (pelanggan) yang sudah setia (loyal) akan tetap membeli walaupun harga lebih mahal, bisa mengajak orang lain untuk membeli brand tersebut, tidak bisa melihat brand lain, bahkan mau dimanfaatkan jika suatu saat terjadi brand erosion.

Untuk menjadi seorang pelanggan yang loyal, seorang konsumen harus melalui beberapa tahapan. Proses ini berlangsung lama, dengan penekanan dan perhatian yang berbeda-beda untuk masing-masing tahap, karena setiap tahap mempunyai kebutuhan yang berbeda. Dengan memperhatikan masing-masing tahap dan memenuhi kebutuhan dalam setiap tahap tersebut, perusahaan mempunyai peluang yang lebih besar untuk membentuk calon pembeli menjadi konsumen loyal dan klien perusahaan.

Menurut Oliver (1997: 392), ada empat tahap loyalitas, yaitu:

(1) Cognitive Loyalty (loyalitas berdasarkan kesadaran). Pada tahap pertama loyalitas ini, informasi yang tersedia mengenai suatu produk/ jasa menjadi faktor penentu. Tahap ini berdasarkan pada kesadaran dan harapan konsumen. Namun bentuk kesetiaan ini kurang kuat karena konsumen mudah beralih kepada produk/jasa yang lain jika memberikan informasi yang lebih menarik.

(2) Affective Loyalty (loyalitas berdasarkan pengaruh) Pada tahap ini loyalitas memiliki kedudukan pengaruh yang kuat baik dalam perilaku maupun sebagai komponen yang mempengaruhi kepuasan. Kondisi ini sangat sulit untuk dihilangkan karena kesetiaan sudah tertanam dalam pikiran konsumen bukan hanya sebagai kesadaran atau harapan.

(3) Conative Loyalty (loyalitas berdasarkan komitmen). Tahap loyalitas ini mengandung komitmen perilaku yang tinggi untuk melakukan pembelian suatu produk atau jasa. Hasrat untuk melakukan pembelian ulang atau bersikap loyal merupakan tindakan yang dapat diantisipasi namun tidak disadari.

(4) Action Loyalty (loyalitas dalam bentuk tindakan). Tahap ini merupakan tahap terakhir kesetiaan. Pada tahap ini diawali dengan suatu keinginan yang disertai motivasi, selanjutnya diikuti oleh siapa pun untuk bertindak dan keinginan untuk mengatasi seluruh hambatan untuk melakukan tindakan.

Sementara Griffin (1995: 35) membagi loyalitas pelanggan dari tahap Suspect sampai Advocates. Untuk lebih jelas dapat dilihat pada gambar di bawah ini.

Cara kerja Profit Generator System adalah sebagai berikut: Perusahaan memasukkan seluruh suspect ke dalam sistem pemasarannya, dan para suspect ini kemudian akan tersaring menjadi quali-

Gambar 1.

Profit Generator System

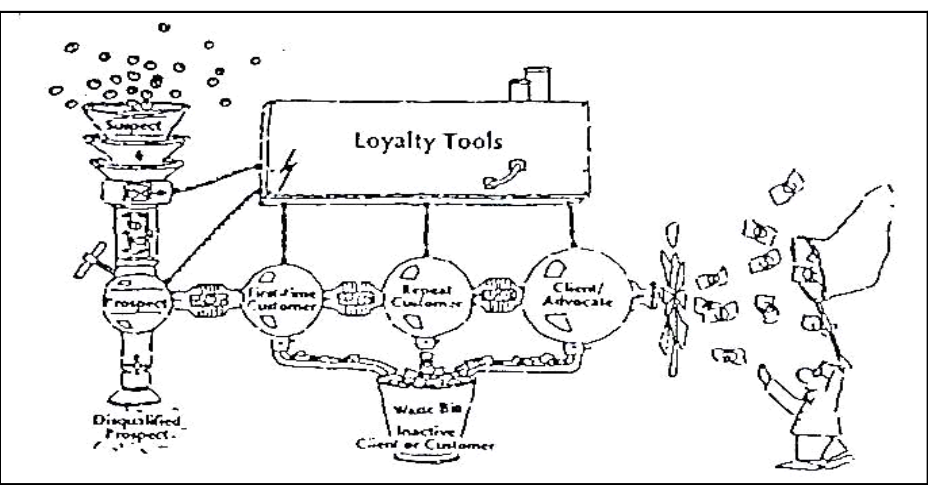

Sumber : Griffin (1995: 36) 
fied prospecy dan disqualified prospect. Disqualified prospect ini dikeluarkan dari sistem, sementara qualified prospect dimasukkan ke proses selanjutnya. Semakin cepat menentukan disqualified prospect, semakin menguntungkan bagi perusahan karena hanya akan menghabiskan uang dan waktu saja. Para qualified prospect kemudian difokuskan untuk menjadi first time buyers, setelah itu mereka didorong untuk menjadi repeat customers, dan selanjutnya loyal clients dan yang paling akhir yang menjadi tujuan dari kegiatan ini yaitu menjadikan mereka sebagai advocates bagi perusahaan.

Para advocates akan mendatangkan profit bagi perusahaaan, karena selain mereka telah menjadi pelanggan setia perusahaan, mereka juga akan mempengaruhi orang lain agar membeli produk dari perusahaan. Pada gambar di atas, terlihat inactive customer client, yang tidak kembali lagi. Hal ini harus diperhitungkan karena dalam setiap tahap perusahaan akan kehilangan sebagian dari mereka dan berarti kerugian pula bagi perusahaan.

Tahapan loyalitas perlanggan ini menurut Griffin (1995: 35), dijelaskan sebagai berikut:

(1) Suspect: meliputi semua orang yang mungkin akan membeli barang/jasa perusahaan. Pada tahap ini konsumen akan membeli tetapi belum mengetahui mengenai perusahaaan dan barang/jasa yang ditawarkan.

(2) Prospects: orang-orang yang memiliki kebutuhan akan produk atau jasa tertentu dan mempunyai kemampuan untuk membelinya. Pada tahap ini konsumen belum melakukan pembelian, tetapi telah mengetahui keberadaan perusahan dan barang / jasa yang ditawarkan, karena seseorang telah merekomendasikan barang/jasa tersebut padanya.

(3) Disqualified Prospects: orang yang telah mengetahui keberadaan barang/jasa tertentu, tetapi tidak mempunyai kebutuhan akan barang/jasa tersebut, atau tidak mempunyai kemampuan untuk membeli barang atau jasa tersebut.

(4) First Time Customer: konsumen yang membeli untuk yang pertama kalinya. Pembelian ini masih menjadi konsumen biasa dari barang atau jasa pesaing.

(5) Repeat Customer: konsumen yang telah melakukan pembelian suatu produk sebanyak dua kali, atau membeli dua macam produk yang berbeda dalam dua kesempatan yang berbeda pula.

(6) Clients: membeli semua barang atau jasa yang ditawarkan, yang mereka butuhkan. Hubungan dengan konsumen ini sudah kuat dan berlangsung lama, yang membuat mereka tidak terpengaruh oleh daya tarik produk atau pelayanan pesaing.

(7) Advocates: layaknya klien, advocates membeli seluruh barang atau jasa yang ditawarkan dan dibutuhkan, serta melakukan pmbelian secara teratur. Sebagai tambahan, mereka mendorong orang lain agar membeli barang/jasa tersebut. Ia membicarakan tentang barang atau jasa tersebut, melakukan pemasaran untuk perusahaan tersebut dan membawa konsumen pada perusahaan tersebut.

\section{Pembahasan}

\subsection{Industri Penerbangan di Indonesia}

Persaingan maskapai penerbangan di Indonesia semakin ketat, terutama setelah adanya kebijakan pemerintah yang hanya membatasi tarif batas atas. Dengan demikian, maskapai penerbangan diperkenankan untuk menentukan sendiri tarif terendahnya. Hal ini menyebabkan maskapai penerbangan saling banting harga, untuk mendapatkan respons dari masyarakat.

Persaingan yang cukup kentara, terjadi pada rute Jakarta-Surabaya, yang selama ini dikenal sebagi rute yang paling padat untuk arus barang dan orang. Pada rute ini, maskapai penerbangan lama dan baru seolah berlomba beroperasi, seperti: Garuda, Lion, Efata Papua, Bouroq, Batavia, Mandala, Merpati, dan Star Air.

Konsumen dijalur ini, maupun jalur lainnya sensitif terhadap harga. Hal ini dibuktikan dengan harga tiket yang dijual murah mendapatkan respons yang positif dari konsumen, di mana terdapat kenaikan jumlah penumpang yang cukup signifikan. Berdasarkan data Departemen 
Perhubungan tahun 2003, terlihat bahwa pada 1999, jumlah penumpang sebesar 731.420 , sementara, tahun 2003, mencapai 2.468.237 penumpang.

Hasil survei yang dilakukan Singapore Airlines pada tahun 1997, mengindikasikan 12 faktor utama yang mempengaruhi pilihan calon penumpang terhadap jasa penerbangan yang tersedia. Faktor-faktor tersebut adalah:
Rute Jakarta - Surabaya, yang merupakan salah satu rute penerbangan jarak pendek, pilihan konsumen pada penerbangan jarak dekat ini dipengaruhi oleh berbagi faktor. Hasil survey OAG Worldwide Business Travel Lifestyle pada tahun1999, mengindikasikan faktor-faktor yang mempengaruhi pilihan penumpang berdasarkan jarak tempuh penerbangan. Adapaun factor-faktor yang mempengaruhi penumpang dapa

Tabel 1.

Faktor yang Memengaruhi Konsumen dalam Pemilihan Layanan Pelanggan

\begin{tabular}{|c|l|c|}
\hline No. & \multicolumn{1}{|c|}{ FAKTOR } & PENGARUH \\
\hline 1. & Ketepatan waktu penerbangan & $76 \%$ \\
2. & Pelayanan yang memuaskan di udara & $59 \%$ \\
3. & Pesawat terbang yang unggul & $52 \%$ \\
4. & Tempat duduk yang nyaman & $48 \%$ \\
5. & Reservasi yang efisien & $44 \%$ \\
6. & Potongan harga & $43 \%$ \\
7. & Pelayanan check-in yang bagus & $43 \%$ \\
8. & Kabin yang bersih & $38 \%$ \\
9. & Makanan dan minuman yang baik & $36 \%$ \\
10. & Program frequent flier & $28 \%$ \\
11. & Kelas bisnis yang unggul & $26 \%$ \\
12. & First Class yang unggul & $17 \%$ \\
\hline
\end{tabular}

Sumber: The Quest for Global, Singapore Airline, 1997

Tabel 2.

Faktor yang Memengaruhi Konsumen, Penerbangan Jarak Dekat

\begin{tabular}{|l|c|c|c|c|}
\hline \multicolumn{1}{|c|}{ FAKTOR } & SEMUA KELAS & FIRST CLASS & BISNIS & EKONOMI \\
\hline Skedul & $51 \%$ & $56 \%$ & $52 \%$ & $48 \%$ \\
Program frequent flier & $26 \%$ & $26 \%$ & $28 \%$ & $23 \%$ \\
Tarif yang murah & $25 \%$ & $18 \%$ & $18 \%$ & $33 \%$ \\
Kebijakan perjalanan dinas perusahaan & $16 \%$ & $15 \%$ & $15 \%$ & $18 \%$ \\
Ketepatan waktu & $15 \%$ & $12 \%$ & $17 \%$ & $! 3 \%$ \\
\hline
\end{tabular}

Sumber: Note on the European Airline Industry, INSEAD 2003. 
penerbangan jarak dekat dapat dilihat pada tabel 2 di bawah ini:

Dengan membaiknya pertumbuhan ekonomi, dimana pada tahun 2003 jumlah penumpang pesawat bisa mencapai 15 juta penumpang, maka pada tahun berikutnya diperkirakan akan bertambah $25 \%$ nya. Jumlah penumpang ini akan dilayani oleh minimal 31 perusahaan penerbangan (Kompas, Agustus 2002). Adapun perusahaan penyediaan fasilitas pendukung.

(4) Dukungan pelayanan terkait dengan operasi penerbangan

(5) Konsultasi, pendidikan, dan pelatihan terkait dengan transportasi udara

Untuk transportasi udara terjadwal, Garuda Indonesia lebih dulu meluncurkan Garuda regular. Namun, sejak adanya kebijakan tarif batas atas tahun 2001, Garuda meluncurkan produk barunya,

Tabel 3.

Perusahaan Penerbangan di Indonesia, Agustus 2002

- PT. Garuda Indonesia

- PT. Merpati Nusantara Airlines

- PT. Kartika Airlines

- PT. Bouroq Indonesia

- PT. Mandala Airlines

- PT. Air Paradise

- PT. Metro Batavia

- PT. Pelita Air Service

- PT. Air Wagon Air

- PT. Lion Mentari Airlines

- PT. Multi Udara Nusantara

- PT. Cartenz papua

- PT. Internusa Air

- PT. Indonesian Airlines

- PT. Trans Wisata Air
- $\quad$ PT. Seulawah NAD Air

- PT. Tri MG Intra Asia Airlines

- PT. Pos Express Prima

- PT. Manunggal Air Service

- PT. Star Air

- PT. Bali Internasional Air

- PT. Bayu Indonesia Air

- PT. Airmark Indonesia

- PT. Jatayu Gelang Sejahtera

- PT. Republic Express Airlines

- PT. Pelita Air Service

- PT. Airfast Indonesia

- PT. Deraya Air Taxi

- PT. Dirgantara Air Service

- PT. Trigana

- PT. Nurman Avia Indopura penerbangan yang meramaikan industri penerbangan di Indonesia sebagai berikut:

\subsection{Citilink}

Garuda Indonesia sebagai perusahaan pertama di bisnis penerbangan dan menjadi market leader di industri ini, menjalankan bisnisnya di ruang lingkup:

(1) Transportasi udara terjadwal, baik domestik, maupun internasional, untuk penumpang komersial, kargo, dan surat.

(2) Transportasi udara tidak berjadwal, domestik dan internasional, untuk penumpang komersial dan kargo

(3) Perbaikan dan perawatan pesawat milik Garuda maupun perusahaan penerbangan lainnya dan yakni Citilink. Citilink merupakan produk Garuda yang diposisikan sebagai penerbangan low fare. Citilink diluncurkan pada 16 Juli 2001 dengan menggunakan pesawat Fokker F-28 dan Boeing 737. Sistem reservasi yang digunakan telah memanfaatkan kemajuan teknologi telekomunikasi dan informasi yang berbeda dengan sistem reservasi konvensional, di mana calon penumpang harus datang ke loket-loket penjualan tiket atau agen-agen penjualan. Sistem reservasi Citilink menggunakan beberapa metode, diantaranya Citilink Prepaid Card dan transaksi online berbasis internet.Kondisi di atas memungkinkan Garuda memposisiskan Citilink sebagai low cost carrier. 
Citilink menerapkan strategi point-to point dalam pelayanannya. Layanan ini ditujukan bagi segmen menengah ke bawah. Pada bulan April 2004, Citilink melayani berbagai rute (pergi-pulang) penerbangan komersial domestik, salah satunya rute Jakarta-Surabaya.

Pada awalnya, Citilink hanya dimaksudkan untuk utilisasi pesawat Fokker F-28 yang tidak terpaCitilink. Namun, pada 2004, Citilink mendapatkan dukungan penuh dari pihak manajemen. Armada yang semula berjumlah lima pesawat F-28, pada tahun 2003 ditambah menjadi dengan 15 pesawat baru Boeing B-737 berkapasitas 300 tempat duduk.

\subsection{Rute Jakarta-Surabaya}

Dengan menggunakan pesawat, rute JakartaSurabaya yang berjarak $778 \mathrm{~km}$, dapat ditempuh hanya dengan waktu 1 jam saja. Selain dengan penerbangan, rute ini juga dilayani oleh jasa angkutan darat (yaitu: kereta api dan bus) dan jasa angkutan laut. Pada Februari 2003, tarif referensi penerbangan sebesar Rp 400/penumpang/ km. Tarif batas atas ditetapkan sebesar Rp778.000/ penumpang.

Pada Maret 2004, tercatat ada sembilan perusahaan penerbangan pada jalur ini dengan harga tiket berada pada kisaran yang sama untuk tiap operator, kecuali Garuda regular.

\subsection{Mengelola Hubungan dengan Pelanggan Citilink}

Pengelolaan hubungan dengan pelanggan Citilink dapat dilakukan dengan:

(1) Menciptakan nilai bagi pelanggan Citilink, yang tidak saja untuk memaksimalkan pendapatan dari transaksi tunggal. Citilink perlu menciptakan nilai pelanggan, tidak saja karena tarif yang murah, tetapi kemampuan Citilink untuk membantu pelanggan menghasilkan nilai untuk mereka sendiri dan untuk membina hubungan jangka panjang dengan pelanggan. Dengan demikian Citilink memiliki keunggulan bersaing dengan maskapai penerbangan lainnya di kelas yang sama.

(2) Citilink perlu dilihat sebagai suatu entitas yang mencakup pertukaran antara proses yang dijalankan oleh provider dengan proses yang dijalankan oleh pelanggan. Melalui pertukaran ini, kompetensi provider dipindahkan ke dalam penciptaan nilai pelanggan. Oleh karena itu, diferensiasi produk menjadi diferensiasi proses sehingga membuka peluang yang menghasilkan berbagai macam hubungan.

(3) Citilink dapat membina hubungan yang lebih kuat hanya jika perusahaan bertanggung jawab dalam membangun hubungan tersebut dan menawarkan pelanggannya untuk

Tabel 4.

Tarif Penerbangan Jakarta-Surabaya, Maret 2004

\begin{tabular}{|l|l|l|l|}
\hline No. & MASKAPAI & FREKUENSI & TARIF \\
\hline & Citilink & $5 \mathrm{X} /$ hari & $\mathrm{Rp} 160.000,00$ \\
2. & Lion & $11 \mathrm{X} /$ hari & $\mathrm{Rp} \mathrm{199.000,00}$ \\
3. & Efata Papua & $1 \mathrm{X} /$ hari & $\mathrm{Rp} \mathrm{160.000,00}$ \\
4. & Bouroq & $6 \mathrm{X} /$ hari & Not Available \\
5. & Batavia & $3 \mathrm{X} /$ hari & $\mathrm{Rp} \mathrm{165.000,00}$ \\
6. & Mandala & $3 \mathrm{X} /$ hari & $\mathrm{Rp} \mathrm{179.000,00}$ \\
7. & Merpati & $1 \mathrm{X} /$ hari & $\mathrm{Rp} \mathrm{226.000,00}$ \\
8. & Star Air & $3 \mathrm{X} /$ hari & $\mathrm{Rp} \mathrm{201.000,00}$ \\
9. & Garuda Reguler & $15 \mathrm{X} /$ hari & $\mathrm{Rp} \mathrm{289.000,00}$ \\
\hline
\end{tabular}

Sumber: Cases in Management-UI, 2006 
menghasilkan nilai-nilai untuk mereka sendiri.

Manajemen hubungan pelanggan fokus dalam menghasilkan nilai optimal bagi para pelanggan melalui:

\section{1) Bagaimana cara Citilink berkomunikasi dengan pelanggan?}

Komunikasi pada pelanggan penting untuk dijalin. Mulai dari penataan komunikasi antarpersona, hingga komunikasi massa. Seluruh personil yang terlibat dalam penyampaian jasa perlu dilatih keterampilan komunikasinya. Sebab, dalam perusahaan jasa, personil penyampai jasa dianggap sebagai wakil perusahaan, sehingga semua personil perlu memiliki kemampuan komunikasi yang baik.

Berbeda dengan konsep komunikasi pemasaran konvensional, menurut Zeithaml dan Bitner (2003: 447), dalam komunikasi pemasaran jasa, perusahaan jasa harus menambahkan konsep komunikasi pemasaran tradisional atau promotion mix yang fokus pada bagaimana cara pelanggan menerima informasi tentang jasa melalui:

(1) Komunikasi Pemasaran Eksternal (External Marketing Communication)

(2) Komunikasi Pemasaran Internal (Internal Marketing Communication)

Gambar 2

"Communications and the Services Marketing Triangle"

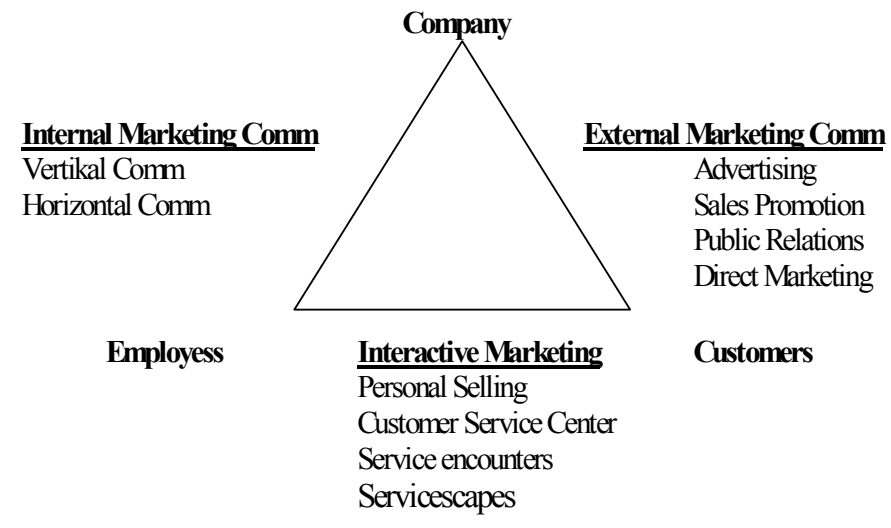

Sumber: Zeithaml dan Bitner, 2003 :447
(3) Pemasaran Interaktif (Interactive Marketing Communication)

Untuk lebih jelasnya, komunikasi pemasaran jasa dapat dilihat pada gambar di bawah ini.

Penjelasan

\section{(1) External Marketing Communication}

(a) Advertising is any pad form of non personnal presentation and promotion of a company's offering by an identified sponsor (Zeithaml dan Bitner, 2003: 449). Bentuk-bentuk advertising, meliputi: iklan cetak dan radio, kemasan luar, kemasan sisipan, surat, katalog, film, majalah, booklet dan brosur, poster dan selebaran, buku alamat dagang, papan iklan, papan nama, pameran pembelian, audiovisual, simbol dan logo.Citilink dapat menggunakan bentuk-bentuk iklan di atas, untuk membantu Citilink memposisikan produknya di benak pelanggan.

(b) Sales Promotion is short-term incentives such as coupons, premiums, or discount that stimulate customer purchase (Zeithaml dan Bitner, 2003: 449). Promosi Penjualan dapat ditempuh Citilink dengan cara memberikan insentif jangka pendek, seperti kupon, premium, ataupun diskon untuk mendorong pembelian konsumen.

(c) Public Relations is building a favourable company image with firm's publics though publicity, relations with the news media and community events (Zeithaml dan Bitner, 2003: 449). Kegiatan public relations perlu dilakukan sebaga salah satu upaya untuk membentuk citra Citilink yang positif. Hal ini dapat dilakukan dengan membuat sebuah publisitas, hubungan baik dengan berbagai media, dan membuat event-event tertentu untuk membangun image yang favourable.

(d) Direct marketing is the use 
of mail, telephone, fax, e-mail and other non personal tools to communicate directly with specific consumers to obtain a direct response (Zeithaml dan Bitner, 2003: 449). Pemasaran langsung dapat dilakukan Citilink agar perusahaan mendapatkan respons langsung dari pelanggan, baik melalui surat langsung, telepon, fax, ataupun email.

\section{(2) Interactive Marketing}

(a) Personal Selling is personal presentation by a representative form the firm to make sale and buy a customer relationship (Zeithaml dan Bitner, 2003: 449). Penjualan personal merupakan bentuk komunikasi pemasaran yang paling klasik. Upaya ini bisa dilakukan agar terjadi proses jual beli, antara Citilink dengan pelanggan.

(b) Customer service is the service provided in support of a company's core product (Zeithaml dan Bitner, 2003: 4). Customer service seringkali melibatkan aktivitas, seperti: menjawab pertanyaan, menerima order, memberi persetujuan rekening tagihan, penanganan komplain, serta penjadwalan perawatan dan perbaikan. Customer service dapat melakukan kegiatannya, baik dengan duduk di kursi kerjanya, melalui telepon, ataupun melalui internet. Bahkan, banyak customer service pada perusahaan perusahaan besar beroperasi 24 jam. Kualitas customer service sangat penting dalam membangun hubungan baik dengan pelanggan. Customer service center perlu dikelola dengan baik. Petugas tidak hanya menerima order dan sebagai pusat informasi Citilink bagi pelanggan, namun juga sebagai pusat penanganan keluhan pelanggan. Jadi, bukan hanya menerima komplain, tetapi bagaiamana complain itu harus ditangani, agar di kemudian hari, pelanggan yang tidak puas tidak menceritakannya pada orang lain, tetapi memilih mengadu pada Citilink. Petugas perlu dilatih agar dapat menangani komplain dengan cepat dan tepat. Untuk itu, perlu dibuat prosedur operasi standar untuk penanganan komplain.

(c) Serviceencounter occur every time a customer interact with the service organization (Zeihaml dan Bitner, 2003: 47). Ada tiga tipe service encounters, yaitu: remote encounters, phone encounters, dan face to face encounter. Pada remote encounters, pertemuan dapat terjadi tanpa kontak langsung dengan individu, seperti ketika pelanggan berinteraksi dengan bank via ATM. Phone encounters merupakan tipe pertemuan antara pelanggan dan karyawan melalui telepon. Sedangkan face to face encounter terjadi jika karyawan dan pelanggan melakukan kontak langsung. Pertemuan antara jasa yang disediakan Citilink dengan pelanggan perlu ditata dengan baik. Apalagi dengan adanya berbagai teknologi informasi yang digunakan oleh Citilink seperti penggunaan internet untuk ticketing, fasilitas layanan pesan antar, bahkan telah ada pengembangan ticketing melalui jaringan ATM. Hal ini perlu pengelolaan yang serius dan terintegrasi, sebab di sini awal pertemuan

Tabel 5

"Elements of Physical Evidence"

\begin{tabular}{|l|l|}
\hline \multicolumn{1}{|c|}{ Servicescape } & \multicolumn{1}{|c|}{ Other Tangibles } \\
\hline Facility exterior & Other Tangibles \\
Exterior design & Business cards \\
Signage & Stationery \\
Parking & Billing statemnets \\
Landscape & Reports \\
Surrounding environment & Employee dress \\
Facility interior & Uniforms \\
Interior design & Brochures \\
Equipment & Web pages \\
Signage & Virtual servicescape \\
Layout & \\
Air quality/ temperature & \\
\hline \multicolumn{2}{|c|}{ Sumber: Zeithaml dan Bitner, 2003: 282 }
\end{tabular}


jasa itu terjadi.

(d) Servicescape. Jasa yang tidak berwujud ini, menyebabkan pelanggan mempercayai sejumlah petunjuk yang tangible atau physical evidence, untuk mengevaluasi sebelum jasa dikonsumsi dan untuk menilai kepuasan selama dan setelah jasa dikonsumsi. Secara umum bukti fisik dapat dilihat pada tabel di bawah ini, dimana pada tabel ini diperlihatkan servicescape (fasilitas fisik) sebagai bentuk dari komunikasi yang berwujud.

Elemen-elemen yang memengaruhi pelanggan melibatkan atribut eksterior (seperti: signage, parking, dan landscape) dan atribut interior seperti desain, layout, perlengkapan, dan dekorasi). Sebagai catatan, web pages dan virtual servicescapes disampaikan melalui internet, di mana menunjukkan sejauhmana Citilink profesional mengelola jasanya. Pelanggan seringkali menarik kesimpulan atas jasa yang akan mereka dapatkan, hanya dengan melihat fasilitas dan bukti fisik yang ada.

\section{(3) Internal Marketing Communication}

(a) Vertical communication, yaitu komunikasi antara karyawan Citilink dan perusahaan dalam rangka persetujuan tentang apa yang disampaikan kepada pelanggan.

(b) Horizontal communication, yang merupakan komunikasi antar departemen dan area-area dalam perusahaan.

Dalam kegiatan internal marketing communication, dimana terjadi komunikasi vertikal dan horizontal, maka aspek yang perlu diperhatikan adalah karyawan sebagai penyedia jasa. Dalam

Gambar 2

The Service Profit Chain

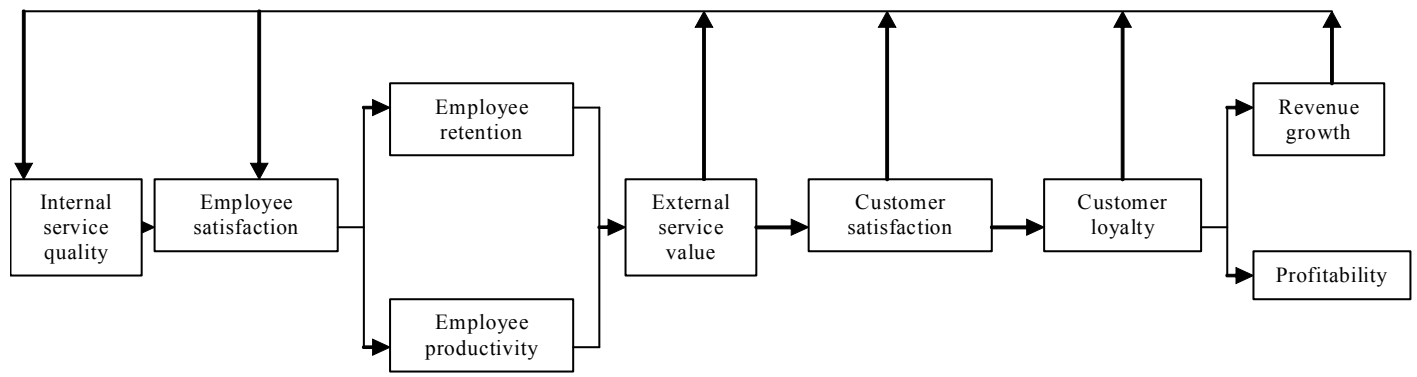

Sumber: J. L Heskett, T.O. Jones, G.W. Loveman, W.E. Sasser, Jr., dan L.A. Schlesinger, 1994

perusahaan dapat mengkomunikasikan pengalaman jasanya, membuat jasa lebih berwujud kepada pelanggan, baik sebelum atau sesudah pembelian.

Servicescape perlu dikelola dengan baik. Kenyamanan selama perjalanan merupakan sesuatu yang perlu dipertaruhkan, untuk memastikan bahwa pelanggan akan mengulang pembeliannya. Servicescape bukan hanya pada saat perjalanannya saja, namun juga air port yang ada perlu pembenahan. Bukti-bukti fisik ini pemasaran jasa, kepuasan tidak saja pada pihak pelanggan, tetapi juga harus diperoleh karyawan, karena dapat mempengaruhi pertumbuhan revenue dan profitabilitas perusahaan. The Service Profit Chain disajikan di bawah ini:

Komunikasi pemasaran internal, sangat penting dikelola. Kepuasan karyawan akan menjadi titik awal bagaiamana pelayanan yang akan diberikan pada pelanggan. Kualitas pelayanan internal Citilink akan memengaruhi kepuasan 
karyawan, yang pada akhirnya berpengaruh pada produktivitas dan retensi karyawan, yang juga akan berpengaruh pada pelayanan kepada pelangggan. Pelanggan yang puas dan loyal tentu akan menjadikan Citilink berkembang dan mendapatkan profitabilitas yang tinggi.

Oleh karena itu, dalam rangka peningkatan profitabillitas Citilink, mengomunikasikan jasa bukan hanya pada pelanggan, namun juga harus dikomunikasikan pada karyawan. Sebab, kepuasan pelanggan pada jasa yang disediakan, sangat dipengaruhi bagaimana dan oleh siapa jasa itu disampaikan.

Menurut Zeithaml dan Bitner (2003: 449) langkah-langkah membangun komunikasi pemasaran jasa yang efektif terdiri dari:

(1) Select the target audience. Dalam setiap kegiatan komunikasi pemasaran yang dilakukan Citilink perlu memperhatikan siapa yang menjadi pelanggan potensial, pengguna penerbangan saat ini, dan siapapun yang dapat mempengaruhi keputusan pembeli untuk menggunakan jasa Citilink.

(2) Determine the communication objectives. Tujuan kegiatan komunikasi pemasaran yang dilakukan Citilink perlu melibatkan berbagai aspek psikologis calon pengguna maupun pengguna jasa penerbangan, seperti: tujuan untuk meningkatkan kesadaran, pengetahuan, kesukaan, preferensi, keyakinan, atau pembelian.

(3) Decide on a budget. Kegiatan komunikasi pemasaran yang dilakukan Citilink perlu disesuaikan dengan anggaran yang ada. Alokasi setiap jenis promosi perlu diketahui dengan pasti dan dihitung secara seksama. Sebagai perusahaan yang berorientasi bisnis, Citilink perlu memperhitungkan profitabilitas yang akan diperoleh, jika sebuah kegiatan komunikasi pemasaran dilakukan.

(4) Create a massage. Pesan komunikasi pemasaran yang dilakukan Citilink melibatkan apa yang akan dikatakan, bagaimana mengatakannya, dan kepada siapa pesan itu akan dikirimkan. Dalam setiap kegiatan komunikasi pemasarannya perlu diusung sebuah tema yang akan ditancapkan pada benak pelanggan. Misalnya: Service Excellence. Pesan dapat berupa pesan verbal (ujaran atau tulisan), nonverbal (fotografi, ilustrasi, logo atau simbol), atau kombinasi dari keduanya.

(5) Collectfeedback. Setiap kegiatan komunikasi pemasaran yang dilakukan citilink harus selalu dievaluasi. Evaluasi ini melibatkan pencarian kembali bagaimana efektivitas komunikasi dibandingkan dengan tujuan yang ingin dicapai. Feedback merupakan komponen penting dalam kegiatan komunikasi pemasaran jasa. Dengan mengatahuifeedback, pengirim pesan akan mengetahui apakah pesan yang disampaikannya memperkuat informasi yang sudah ada, mengubah pesan yang telah sampai kepada konsumen, atau memodifikasi pesan yang telah diterima konsumen. Feedback lebih mudah dipahami dalam kegiatan komunikasi interpersonal.Misalnya, salesman dapat melihat feedback dari ekspresi wajah konsumen atau pun gerakan tubuhnya. Sementara itu, untuk kegaiatan komunikasi pemasaran jasa melalui media massa, feed back nya sulit untuk diketahui. Citilink dapat mengetahuinya dengan melakukan riset kepada konsumen/pelanggan. Misalnya dengan advertising effectiveness research.

Saat ini, perusahaan jasa biasanya mengadopsi Integrated Marketing Communications (IMC), di mana yang diintegrasikan adalah seluruh saluran komunikasi eksternal saja. IMC untuk jasa lebih kompleks dari pada barang. Dalam Integrated Service Marketing Communications (ISMC), tidak saja komunikasi melalui saluran eksternal yang diintegrasikan, namun juga melibatkan komunikasi pemasaran melalui saluran internal dan komunikasi pemasaran interaktif, untuk memproduksi jasa yang dijanjikan kepada pelanggan. Oleh karena itu, saluran komunikasi pemasaran internal harus dikelola, sehingga karyawan dan citilink setuju dengan apa yang dikomunikasikan kepada pelanggan. ISMC mensyaratkan setiap orang terlibat dengan komunikasi yang jelas, pemahaman antara strategi pemasaran perusahaan dan janjinya kepada 
konsumen.

Ada empat pendekatan untuk Integrated Service Marketing Communications Zeithaml dan Bitner (2003: 459), yakni:

(1) Manage service promises: melibatkan integrasi mengenai janji yang dibuat oleh Citilink dalam komunikasi pemasaran eksternal dan pemasaran interaktif untuk memastikan bahwa Citilink dapat konsisten dengan janjinya dan juga dapat mengerjakannya.

(2) Manage customer expectations: menjelaskan kepada pelanggan bahwa Citilink tidak selalu dapat menyediakan level jasa yang diharapkan. Jasa yang diberikan perlu dinegosiasikan dengan ekspektasi pelanggan yang tidak realistik. Untuk itu, perlu mengkomunikasikan kriteria pelayanan yang diberikan Citilink kepada pelanggan.

(3) Improve customer education: Menyediakan informasi tentang proses jasa dan kriteria evaluatif mengenai aspek penting dalam jasa. Citilink perlu mengkonfirmasikan performa standar jasanya, mengklasifikasi harapan setelah penjualan, dan mendidik pelanggan untuk menghindari periode sibuk, dan berpindah ke periode tidak sibuk, agar dapat diberikan pleayanan sesuai standar.

(4) Manage internal marketing communication. Internal marketing communication dapat dilakukan secara vertikal maupun horizontal. Komunikasi vertikal melibatkan down ward communication, dari manajemen ke karyawan atau up ward communications adalah komunikasi antar fungsi dalam Citilink.

\section{2) Bagaimana perusahaan memasarkan} Citilink?

Pada prinsipnya, pemasaran jasa Citilink mengutamakan aspek-aspek berikut: ketepatan waktu penerbangan, pelayanan yang memuaskan di udara, pesawat terbang yang unggul, tempat duduk yang nyaman, reservasi yang efisien, potongan harga, pelayanan check-in yang bagus, kabin yang bersih, makanan dan minuman yang baik, program frequent flier, kelas bisnis yang unggul, keamanan yang terjamin, kebijakan perjalanan dinas perusahaan, dan tarif yang murah.
Cara-cara pemasaran dapat dilukakn dari mulai yang paling konvensional, yakni personal selling, hingga pemasaran yangberbasis internet. Citilink nampaknya sudah melakukan pemasaran yang modern, namun perlu diwaspadai saluran-saluran yng digunakan untuk kegiatan pemasarannya.

3) Bagaimana Citilink melayani pelanggan?

Pelayanan yang diberikan Citilink harus memuaskan pelanggan. Pelayanan yang memuaskan akan mengakibatkan penggunaan jasa Citilink secara terus menerus, sehingga tercipta loyalitas pelanggan. Citilink perlu memiliki kemampuan mengelola harapan pelanggan dan kinerjanya, misalnya memberlakukan tarif murah pada waktu-waktu tertentu tanpa mengurangi kinerja pelayanannya. Harapan pelanggan perlu dikelola sesuai dengan kinerja yang sekiranya dapat diberikan oleh Citilink. Penerapan pelayanan yang baik seperti: tangible, empathy, responsivness, reliability, dan assurance, perlu terus digalakan.

Zeithaml, Parasuraman, dan Bitner (1990: 26), mengemukakan, ada lima dimensi pokok kualitas pelayanan yang meliputi:

(1) Tangibles. The appearance of physical facilities, equipment, personnel, and communication material.

(2) Reliablity, The ability to perform the promised service dependably and accurately.

(3) Responsiveness. The willingness to help customers and provide prompt service.

(4) Assurance. The knowledge and courtesy of employees and their ability to convey trust and confidence.

(5) Empathy. The caring individualized attention the firm provides its customers.

Kualitas jasa penerbangan Citilink mencakup: dimensi tangible, yang meliputi: kelayakan fasilitas fisik, kebersihan kabin, dan kerapihan pakaian karyawan; dimensi empathy, meliputi: kemampuan karyawan berkomunikasi, pemahaman karyawan pada kebutuhan penumpang, dan kemudahan karyawan untuk dihubungi; dimensi reliability, meliputi: ketepatan waktu pelayanan dan ketepatan pelayanan; dimensi responsiveness, meliputi: 
kesediaan karyawan membantu tamu dan kecepatan pelayanan; dan dimensi assurance, meliputi: kompetensi karyawan dan kredibilitas karyawan.

Pihak manajemen Citilink perlu terus memotivasi personilnya untuk dapat memberikan pelayanan terbaik kepada pelanggan, sehingga diharapkan pelanggan dapat terus menggunakan jasa Citilink. Citilink tentu harus mengupayakan pelanggannya masuk dalam kategoti repeat customer, client, atau advocates, yang tentu saja akan lebih profitable bagi perusahaan.

4) Bagaimana menata bauran pemasaran jasa? Integrasi secara optimum pada aspek-aspek pemasaran Citilink sangatlah diperlukan. Aspekaspek bauran pemsaran jasa yang perlu ditata meliputi, produk, harga, saluran distribusi, promosi, people, proses, dan fasilitas fisik. Loyalitas pelanggan akan dapat dipertahankan jika seluruh aspek pemasaran sinergi, mulai dari produk yang baik, harga yang terjangkau, fasilitas ticketing yang baik, promosi yang tepat, ruang tunggu yang nyaman, hingga pelayanan yang excellence.

\subsection{Loyalitas Pelanggan Citilink}

Loyalitas pelanggan Citilink merupakan tujuan dari pengelolaan hubungan dengan pelanggan. Loyalitas pelanggan Citilink merupakan pembelian pelanggan pada jasa Citilink yang digambarkan sebagai persentase total pembelian jasa Citilink. Loyalitas pelanggan merupakan komitmen untuk bertahan secara mendalam dengan melakukan pembelian ulang atau berlangganan Citilink secara konsisten di masa yang akan datang, meskipun pengaruh situasi dan usaha-usaha pemasaran mempunyai potensi untuk menyebabkan perubahan perilaku.

Loyalitas pelanggan Citilink dicirikan dengan empat hal berikut :

(1). makes regular repeat purchase (melakukan pembelian ulang). Jadi, penumpang Citilink bersedia untuk menggunakan jasa penerbangan ini lebih dari satu kali. Semakin sering jasa Citilink digunakan, maka pelanggan dianggap semakin loyal pada jasa Citilink. Untuk memastikan pelanggan tetap menggunakan Citilink dalam jangka waktu yang panjang, perusahaan dapat mengikatnya dengan member card.

(2) purchases across product and service lines (membeli di luar lini produk atau jasa). Penumpang Citilink perlu dipersuasi agar tidak saja menggunakan jasanya ketika akan melakukan perjalanan Jakarta-Surabaya, namun juga tetap menggunakan jasa ini untuk rute Citilink lainnya. Bahkan lebih jauh, pelanggan Citilink juga bersedia menggunakan jasa lain yang ditawarkan Garuda Indonesia, seperti Garuda regular untuk penerbangan internasional, kargo, atau express mail.

(3) refers others (menarik pelanggan baru untuk perusahaan). Pelanggan Citilink perlu dipersuasi untuk dapat menarik pelanggan baru. Citilink perlu memberikan insentifjangka pendek untuk mendongkrak penjualan. Misalnya dengan program buy 1 get 1 free, potongan $30 \%$ bagi penumpang yang dapat membawa 5 orang relasi bisnis, teman, atau kerabatnya, dan sebagainya. Apabila pelanggan puas dengan pelayanan yang diberikan oleh Citilink, maka pelanggan akan merekomendasikan Citilink pada orang-orang terdekatnya, agar mereka pun mau menggunakan Citilink.

(4) demonstrates an immunity to the pull of the competition (menolak produk / jasa lain, dan kebal terhadap daya tarik pesaing). Pelanggan Citilink yang loyal, tentu akan selalu menggunakan jasa Citilink dan menolak tawaran dari maskapai penerbangan lainnya. Oleh karena itu, agar tidak terjadi penggunaan jasa peerbangan lainnya, Citilink perlu membuat jadwal keberangakatan yang optimum untuk pelanggannya. Kalau pun pelanggan ini mencoba maskapai penerbangan lainnya, hanya sekadar memuaskan hasrat ingin mencoba, namun setelah itu, kembali menggunakan Citilink.

Untuk memastikan bahwa pelangggan Citilink tetap loyal, walaupun pada kenyataanya pelanggan bisa saja menerima kinerja jasa 
penerbangan kurang sesuai dengan harapan pelanggan, maka perlu dibuat sistem untuk memuaskan keluhan pelanggan.

Berbagai penelitian tentang ketidakpuasan pelanggan menunjukkan bahwa para pelanggan tidak puas dengan pembeliannya sekitar $25 \%$, tetapi hanya $5 \%$ yang mengeluh, dan $95 \%$ sisanya tidak mengeluh karena menganggap tidak sepadan dengan usahanya/tidak tahu bagaimana atau kepada siapa harus mengeluh.

Dari $5 \%$ pelanggan yang menyampaikan keluhan, hanya sekitar $50 \%$ yang melaporkan pemecahan masalah yang memuaskan. Sedangkan rata-rata seorang pelanggan yang puas memberitahu tiga orang tentang pengalaman produk yang baik, dan rata-rata seorang pelanggan yang tidak puas mengeluh pada sebelas orang. Jika tiap orang dari ke sebelas orang itu memberitahu orang lain lagi, jumlah orang yang mendengar keburukan itu dari mulut kemulut akan bertambah secara eksponensial.

Namun, pelanggan yang keluhannya diselesaikan dengan baik sering menjadi lebih setia pada perusahaan daripada pelanggan yang tidak pernah dipuaskan. Sekitar 34\% pelanggan yang mencatat keluhan besar akan membeli lagi dari perusahaan jika keluhan mereka diselesaikan, dan angka ini naik menjadi 52\% untuk keluhan kecil. Jika keluhan itu diselesaikan dengan cepat, sekitar 52\% (keluhan besar) dan 95\% (keluhan kecil) akan membeli kembali dari perusahaan.

Menurut Griffin (1995: 191), ada empat cara agar tidak ditinggalkan pelanggan, yaitu:

(1) Make it easy for customer to give you feedback. Buat mudah pelanggan untuk mendapatkan feedback.

(2) When customers need help, provide it quickly. Ketika pelanggan memerlukan pertolongan, segera disediakan.

(3) Reduce hassle of repairs and refund and warranties. Kurangi perseteruan dengan pelanggan mengenai perbaikan, pengembalian dan jaminan.

(4) Learn how to comfort and angry customer. Belajar dari kenyamanan dan kemarahan pelanggan.
Oleh karena itu, Citilink perlu mengembangkan program pemulihan pelayanan. Kotler (2003: 457) menyatakan bahwa ada tiga langkah untuk mengembangkan program pemulihan pelayanan, yaitu:

"Langkah pertama perusahaan mengusahakan agar pelanggan yang tidak puas mudah menyampaikan keluhan. Kedua, karyawan perusahaan yang menerima keluhan dilatih dengan baik dan diberi wewenang untk memecahkan masalah pelanggan dengan cepat dan memuaskan. Riset menunjukkan bahwa semakin cepat perusahaan menanggapi keluhan, semakin tinggi kepuasan pelanggan pada perusahaan. Ketiga, perusahaan harus bergerak lebih dari sekedar memuaskan pelanggan tertentu dan menemukan serta memperbaiki akar penyebab masalah yang sering timbul."

Dengan mempelajari pola keluhan, personil Citilink dapat memperbaiki kegagalan sistem yang biasanya menimbulkan keluhan tersebut.

\subsection{Simpulan}

Pelanggan Citilink yang loyal merupakan tujuan dari kegiatan perusahaan untuk menjalin hubungan dengan pelanggan. Oleh karena itu, Citilink perlu mengelola hubungan dengan pelanggan. Manajemen hubungan pelanggan yang perlu dilakukan oleh Citilink adalah:

(1) Berkomunikasi dengan pelanggan dan membina komunikasi antara perusahaan, karyawan dan pelanggan. Komunikasi yang perlu dijalin melliputi, komunikasi pemasaran eksternal, komunikasi pemasaran internal dan pemasaran interaktif.

(2) Meningkatkan upaya pemasaran Citilink. Pemasaran dilakukan beik off line maupun on line. Pemasran modern telah mulai dikembangakan oleh Citilink, namun penatakelolaan infrastruktur saluran pemasaran perlu terus dipelihara.

(3) Citilink melayani pelanggan dengan aspek pelayanan excellence, seperti: tangible, empathy, reliability, responsiveness, dan assurance.

(4) Mengintegrasikan bauran pemasaran jasa, 
seperti: jasa yang baik, harga yang terjangkau, pelayanan yang memuaskan, fasilitas ticketing yang baik, promosi yang tepat, ruang tunggu yang nyaman, dan pelayanan yang $e x-$ cellence.

Manajemen hubungan pelanggan yang tertata akan dapat meningkatkan kepuasan pelanggan dan lebih jauh akan meningkatakan loyalitas pelanggan. Loyalitas pelanggan Citilink dicirikan oleh empat aspek, yakni:

(1) makes regular repeat purchase (melakukan pembelian ulang).

(2) purchases across product and service lines (membeli di luar lini produk atau jasa).

(3) refers others (menarik pelanggan baru untuk perusahaan).

(4) demonstrates an immunity to the pull of the competition (menolak produk / jasa lain, dan kebal terhadap daya tarik pesaing).

Untuk memastikan bahwa pelangggan Citilink tetap loyal, walaupun pada kenyataanya pelanggan bisa saja menerima kinerja jasa penerbangan kurang sesuai dengan harapan pelanggan, maka perlu dibuat sistem untuk memuaskan keluhan pelanggan.

\section{Daftar Pustaka}

Griffin, Jill. 1995. Customer Loyalty: How To Earn It, How To Keep It. USA: Lexington Books

2005. Customer Loyalty: Menumbuhkan \& Mempertahankan Kesetiaan Pelanggan. Terjemahan Dwi Kartini Yahya. Penerbit Erlangga.

Hermawan Kartajaya, dkk. 2002. Markplus on Strategy; 12 Tahun Perjalanan Markplus \& Co Membangun Strategi Perusahaan. Jakarta: PT. Gramedia Pustaka Utama.

Kotler, Philip. 2003 Marketing Management. Eleventh Edition, Prentice Hall International, Inc.

Nykamp, Melinda.2001. The Customer Differential: The Customer Differential: The Com- plete Guide to Implementing Customer Relationship Management. AMACOM: New York.

Oliver, Richard L. 1997. Satisfaction: A Behavioral Perspective on The Consumer. New York: The Mc Graw-Hill Companies, Inc.

Schmitt, Bernd H. 2003. Customer Experience Management. John Wiley \& Sons, Inc:USA.

Subroto B. 2000. "Strategi Mempertahankan Perusahaan di Masa Krisis: Kasus Perusahaan Penerbangan Indonesia," Usahawan No.11 Tahun XXIX November.

Storbacka, Kaj \& Jarmo R. Lethtinen.2001. Customer Relationship Management: Creating Competitive Advantage Through Win-Win Relationship Strategies. McGraw-Hill. Singapore.

Stum, David L. "Getting Serious About Customer Loyalty." Tapping the Network Journal Vol. 5, Iss; pg 5, 3 pgs, Northfield: Fall 1994 / Winter 1995

Tiwana, Amrit. 2001. The Essential Guide to Knowledge Management: E business and CRM Applications. Prentice Hall: USA.

Zeithaml, Valerie A, dan M.J. Bitner. 2003. Service Marketing. Third Edition, USA: Mc. Graw Hill Co, Inc.

Zeithaml, Valerie A., A. Parasuraman and L.L. 1990. Berry. Delivering Quality Service-Balancing Customer Perceptions and Expectations. The Free Press, A division of Macmillan, Inc.

Zikmund, William G, Raymond McLeod, Jr, \& Faye W. Gilbert.2003. Customer Relationship Management: Integrating Marketing Strategy and Information Technology. John Willey \& Sons, Ltd: USA.

\section{Sumber lain:}

Case Center Departemen Manajemen Fakultas Ekonomi Universitas Indonesia. Case in Management-Indonesian's Real Companies. Penerbit Salemba Empat. Jakarta, 2006.

Kompas, 2002. Perusahaan Penerbangan di Indo- 